\title{
Green Building and Energy Conserving Designs: Significance of Timber as a Sustainable Building Material in Nigeria
}

\author{
OSORE Oludare Temitope
}

\begin{abstract}
In recent times alluding to the subject of building projects and the built environmentis not without giving considerable attention to sustainability. The thrust of this paper is to present the significance of timber as a sustainable building material, the advantages of its physical and aesthetic qualities, workability, and environmental impact are highlighted. However this is not without proffering solutions to problems associated with its usage, which include; but not limited to the following: acceptability, fungal attacks, fire resistance etc. In Nigeria, the degree to which timber is being utilized by professionals in the building industry is not only limited to understanding of the material, but also by their perception of the material. An issue that stems mostly from insufficient knowledge about its performance characteristics.Combining the review of relevant literature, and qualitative data collection method, this paper reports on evidence based research. This study therefore concluded that through proper planning, and efficient application of timber in highly valued buildings, the potential for sustainable technologies to develop is likely to be greater than if the material is wasted on low value or poorly designed buildings.
\end{abstract}

Index Terms - Building Material, Nigeria, Significance, Sustainability, Timber.

\section{INTRODUCTION}

Man endeavours to have decent homes within his built environment; this is applicable in both local and urban societies through the utilization of good building materials. [1]. Undoubtedly, the building sector has experienced advancements in designs, which has become a reoccurring phenomenon and as man strived to move from Stone Age to Computer Age; it further influenced the growth, advent of new building materials and modern technology. These new building materials such as steel, glass and concrete have continued to experience an upward surge in demand without taking into cognizance the raw state from which they are manufactured, the renewal solutions for these resources and the negative impacts on the environment resulting in environmental degradation, desertification, desert encroachment and ultimately ecosystem imbalance. The overreliance on these materials, a practice that led to timber being underutilized allowed for buildings expending an incredible amounts of materials, energy and other resources, which in turn leads to continuedenvironmental impacts During the life cycle of a building project right fromconstruction, operation (post -occupancy) and eventual demolition. Hence for a material to be considered sustainable, it must satisfy the following attributes; Natural, Renewable,
Low production energy,Carbon storage capabilities, Good Insulator, Readily available and Flexible[2].Timber is a natural and renewable material, stores carbon through its life cycle, it is easily workable, light \&versatile and has a considerably low production energy resulting in minute emissions into the atmosphere. This as a result, prompted the need to explore implicit nature of timber as a sustainable material.

\section{REVIEW OF LITERATURE}

Timber as a building material is an apt choice, as it is natural and a renewable resource. Beyond the fact that timber stores carbon through its life cycle, it is also recyclable. Timber is a versatile material which is not only sustainable but also attractive and cost effective. If properly utilized it offers both aesthetics and performance. Timber possesses excellent tensile and compressive strengths. Timber like steel and concrete, has its limitations. The properties of timber are anisotropic, they change according to environmental conditions[3]. These properties however can be modified when and if subjected to special treatments which would improve upon its resistance to decay, imperviousness to fire and dimensional stability. An increasing awareness of environmental issues mostly related to global warming has led to a growing interest in making development sustainable in the building sector, particularly in the performance of the building. Environmentally sustainable building design solutions require consideration of broad and complex issues. The utilization of any specific building material, such as timber is incapable of providing a complete design solution, it may however prove a viable, efficient and effective alternative.

\section{TIMBER PROCESSING}

Logs are processed into lumber. The logs are cut into shorter lengths, and these shorter sections are then sawn along their lengthsinto boards. The boards are sawn into lumber giving the desired width and thickness. Waste edges are trimmed to square the edges. Similarly, the waste ends are cut to square the ends. The lumber is then stacked to dry (seasoning).The purpose of seasoning timber is to either expel or dry up the sap embedded in it, which causes it to decay or putrefies it. Seasoning is also done to reduce the weight of timber. The two principal methods of seasoning are Natural seasoning (Air drying) and artificial seasoning (kiln drying). 


\section{Classification\& Physical Properties}

Timber can be classified into softwood or hardwood, depending on the tree from which they come. Woods taken from broad-leaved trees are referred to as hardwoods, while woods from coniferous trees are called softwoods, this is regardless of their actual hardness.Principal physical properties of timber include, strength, density, hardness and stiffness. The term strength varies in timber, this is due to the variation in seasoning, or dryness of the wood. The physical property is the most important when considering it for certain structural forms such as beams, battens, planks, and so forth.

\section{Problems Associated with the Use of Timber}

Many of the disadvantages of using timber are exaggerated, this is as a result of misunderstanding the strength, durability, and other performance characteristics of thematerial. The problems associated with the use of timber in Nigeria stem from the following;

I. Acceptability (a general misconception that timber is cheap and low class)

II. Lack of Quality Control

III. Attacks by Insects, Fungi and Vermin,

IV. Poor fire Resistance

V. Depletion of Natural Resources.

Proffered solutions to the above identified problems are as follows;

I. Composite Timber.

II. Flame Retardant and Preservative Treatments.

III. Concrete enhanced Timber and

IV. Mass production.

\section{Timber as a Structural Material}

Timber members are particularly capable of acting as tension, compression and bending members. Due to its high strength to weight ratio, it is widely used as a structural material for roofs. Albeit in comparison to steel or concrete, the modulus of elasticity is low, this can be counteracted by selecting a stiff structural form. For example a Radiatapine Structural timber, has a strength to weight ratio 20 percent higher than structural steel and 4 to 5 times better than unreinforced concrete in compression, which allows forlarge structures to be built economically in other forms such as domes spanning over $100 \mathrm{~m}[4]$.

Table 1. Similarities and differences between steel and timber as structural materials

\begin{tabular}{|c|c|}
\hline \multicolumn{2}{|l|}{ SIMILARITIES } \\
\hline STEEL & TIMBER \\
\hline Hollow sections & Poles \\
\hline Bars, angles & Sawn timber \\
\hline I-beam & I-beam \\
\hline Sheets & Panels \\
\hline Welding & Gluing \\
\hline Bolting & Bolting \\
\hline \multicolumn{2}{|l|}{ DIFFERENCIES } \\
\hline Isotropic & Anisotropic \\
\hline Manufactured & Grown, graded \\
\hline Uniform & Variable, heterogeneous \\
\hline Affected by temperature & Affected by moisture \\
\hline
\end{tabular}

Source: Presented in Lawson, W.R., 1996, 'Timber in

\section{Building Construction}

\section{Timber as a Sustainable Material}

In simple words, this paper defines sustainable development, as the development that addresses the needs of the present without limiting the ability of the future generations from catering to their own needs. This is not without noting that sustainable development simply means, development without depleting a natural resource. On that note, the mode of conduct of man has experienced a paradigm shift on the accounts that there has been an increased awareness towards the limits of the earth's natural resources and finding renewable solutions for these resources. Inherent in this realization is the aim of utilizing building materials taking into cognizance the question of sustainability. Timber unlike popular building materials such as glass, steel and concrete which require relatively long geological years for replacement, is natural, readily available, renewable, workable and extremely useful even where only basic technology and procedures are available[5].Manufacturing processes create fewer air and water emissions than many of its alternatives; it is totally reusable, recyclable and is $100 \%$ biodegradable. Light, versatile, economical and easy to use.It offers an extensive range of interior and exposed structure and surface uses, including framing, lining, cladding, flooring and roofing in domestic and industrial constructions.

\section{Timber as a Green Material}

The raw material for timber is wood from trees. Trees play significant roles in carbon sequestration thus reducing carbon in the atmosphere. The National Greenhouse Inventory in 1999 estimated that Australian forest growth locked up 23 million tons carbon dioxide (CO2 greenhouse gas) through photosynthesis. Growing plants take carbon from the atmosphere and the earth. An important contribution to reduction in greenhouse gases.Embodied energy measures the total energy used to transform raw materials into final products for building purposes. It is expressed inGigajoules per tonne $(\mathrm{GJ} / \mathrm{t})$ or Mega joules per kilogram $(\mathrm{MJ} / \mathrm{kg})$.

The energy assessment involves four different stages in which material are processed from it raw state to finished products. The stages are:

Stage 1: Energy required in collecting the building materials in its raw state.

Stage 2:Energy required to Manufacture and process into finished products

Stage 3: Environmental Impact from Living in a building constructed with the materials

Stage 4: Energy required to in recycle, reuse and disposal 
Table 2: Fossil fuel energy used in the manufacture ofpopular building materials

\begin{tabular}{|c|c|c|}
\hline Material & $\begin{array}{c}\text { Fossil fuel } \\
\text { energy }(\mathbf{M J} / \mathbf{k g})\end{array}$ & $\begin{array}{c}\text { Fossil fuel } \\
\text { energy }(\mathbf{M J} / \mathbf{m 3})\end{array}$ \\
\hline $\begin{array}{c}\text { Rough sawn } \\
\text { timber }\end{array}$ & 1.5 & 750 \\
\hline Steel & 35 & 266000 \\
\hline Concrete & 2 & 4800 \\
\hline Aluminium & 435 & 1100000 \\
\hline
\end{tabular}

Table 3: CO2 Released and Stored in the manufacturing of popular building materials

\begin{tabular}{|c|c|c|c|}
\hline Material & $\begin{array}{c}\begin{array}{c}\text { Carbon } \\
\text { Expelled } \\
\text { Harvesting }\end{array} \\
\underline{\text { raw }} \\
\underline{\text { Mat. }(\mathrm{kg} / \mathrm{t})}\end{array}$ & $\begin{array}{c}\begin{array}{c}\text { Carbon } \\
\text { Expelled } \\
\text { Processing }\end{array} \\
\frac{\text { raw Mat. }}{\left(\mathrm{kg} / \mathrm{m}^{3}\right)} \\
\end{array}$ & \begin{tabular}{l}
\multicolumn{1}{c}{ Carbon } \\
Stored \\
During \\
processing \\
$\left(\mathbf{k g} / \mathbf{m}^{3}\right)$ \\
\end{tabular} \\
\hline $\begin{array}{l}\text { Rough } \\
\text { sawn } \\
\text { timber }\end{array}$ & 30 & 15 & 250 \\
\hline Steel & 700 & 5320 & 0 \\
\hline Concrete & 50 & 120 & 0 \\
\hline $\begin{array}{l}\text { Alumini } \\
\text { um }\end{array}$ & 8700 & 22000 & 0 \\
\hline
\end{tabular}

Source: Presented in Ferguson, et al., 1996, 'Environmental Properties of Timber".

Tables $2 \& 3$ as seen above, shows fossil energy used in manufacturing some popular building materials, expressed in different units.

Comparing the environmental impact of timber on the environment against popular building materials as presented by [6], as seen in Table 2, without the need for complex analysis, it is apparent that timber at $750 \mathrm{MJ} / \mathrm{m}^{3}$ requires less fossil fuel to manufacture compared to steel, concrete or aluminium and Table 3 reveals that sawn timber expels a meagre $30 \mathrm{Kg} / \mathrm{t}$ of carbon dioxide while storing up to 15 times the amount carbon dioxide expelled during its manufacture, whereas steel and aluminum store a very negligible amount.According to [7] in an article "Embodied Energy" in 2004, stated that it takes timber lesser kilowatt hours of energy consumption to make a finished product with timber requiring $1000 \mathrm{kw} / \mathrm{h}$, Concrete $2500 \mathrm{kw} / \mathrm{h}$, steel $4500 \mathrm{kw} / \mathrm{h}$ and aluminum $20000 \mathrm{kw} / \mathrm{h}$. This undoubtedly qualifies timberas a perfect sustainable building material.

\section{Advantages of Timber as a Building Material}

The advantages of timber as a building material include availability, workability, and environmental sustainability, flexibility of space arrangement, dry construction, industrial production and comparative cost effectiveness [8].

i. Availability and Acceptability

Timber is locally available in most states within the country of the world. It can be purchased from local suppliers and transported to site using vehicles or carts.

ii. Workability and Versatility

Timber can be shaped either by hand or machine tools. It can be cut, planed, routed or chiseled. There are various ways to connect timber to timber or to other materials since timber is easily secured and fastened with nails, screws or bolts.

iii. Dry construction

Unlike concrete floors, timber floors do not require a curing period before achieving maximum strength. Construction is therefore faster. Finishing is also faster, it's polished immediately.

\section{iv. Comparative Cost Effectiveness}

The abundance of wood in most localitiesmakes timber production less dependent on import. Prices are relatively stable, since the volatile foreign exchange markets have less influences.

v. Physical and aesthetic quality

Timber has a high strength to weight ratio making it an attractive framing material. Some species are highly resistant to rot, corrosion and marine damage.

\section{vi. Environmental sustainability}

The most significant environmental benefits of timber is its manufacturing process, energy and emissions [9]. Timber is an excellent insulator against hot or cold weather. The old "log-house" remains a model for minimum energy consumption in buildings [10].

\section{STUDY AREA AND METHODOLOGY}

This evidenced based study is a pruned version of a more detailed research carried out in Nigeria; located in West Africa, with its coast in the south lying on the Gulf of Guinea in the Atlantic Ocean, Nigeria shares land boarders with four countries namely: the Republic of Benin in the West, Chad and Cameroun in the East and Niger Republic in the North. It comprises of 36 states with the Federal Capital Territory Abuja as its capital. Nigeria has an estimated population of about 191 million (National Population Commission, 2016).

The study was carried out withinAkure,Ondo State, situated in South West. It is a random selection made from one of the six geographical zones in Nigeria. This study adopted the Qualitative method of data collection that employs the use of textual and visual analysis, unstructured interviews (individual or group) and observation in order to gauge views and acceptability of timber as a building material.

\section{EVIDENCE BASED RESEARCH}

The case of Universal Basic Education Board Office Block Akure, Ondo State, Nigeria.

The Ondo State Universal Basic Education Board is essentially an old office building in Akure, the capital of Ondo State. The exact date of construction is unknown, but following a series of enquiries, it is assumed that it was built between 1960 and1970. According to the maintenance officer it istouted as being one of the oldest surviving timber built structures in the state. The whole structure consists of frames, a sill frame resting on the concrete foundation, and the four 
wall frames made up of sills, corner posts and wall plate. The timber walls are made of bald cypress on the outside and red cedar inside which are held together by nails. The internal office spaces are separated by 2 thin sheets of plywood with void in-between big enough to serve as an acoustic barrier between 2 office spaces. The office building which is assumed to be over 50 years old has at the time of this study, was yet to receive any preservative treatments however it is imperative to note that after a period of over 50 years, despite the mode of use and weathering effects it has been subjected to, this building made of timber is still standing and still in use. For every piece is locked into position that suffers defects, it is easily replaced by a fresh sawn panel treated with preservatives which takes less than 45 minutes. This is further attesting to qualities of timber as versatile, available and workable which going by this evidence is undoubtedly a sustainable building material.

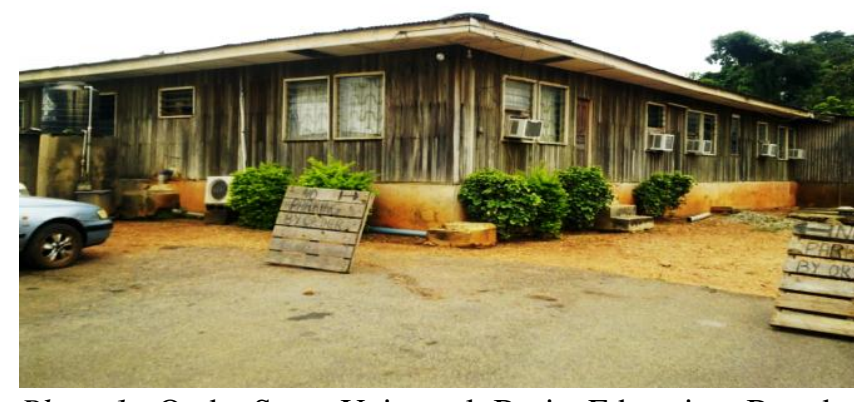

Plate 1: Ondo State Universal Basic Education Board located inAkure, Ondo, Nigeria.

Source: Researchers field survey

\section{CONCLUSION AND RECOMMENDATIONS}

\section{Conclusion}

The problem of or in selecting timber as a sustainable building material stems not just from the insufficient knowledge about its strengths, durability and other performance characteristics, but also the overreliance on the alternatives. Consequent to this realization, the qualities that qualify timber as a sustainable material were highlighted and that if timber is used intelligently and efficiently by architects and builders alike, in durable, highly valued buildings, then the potential for sustainable technologies to improve is likely to be greater than if the material is wasted on temporary, low value or poorly designed buildings.

\section{Recommendations}

Owing to the findings of this study, the following recommendations are suggested

i. Prospective building developers considering the selection of timber as a preferred material for construction should seek the expert advice before undergoing development

ii. The experts on their own part, should make readily available advice on the financial requirements, the benefits and the potentials of timber as a sustainable material.

iii. Developers should take into cognizance, the location and building type before embarking on construction.

iv. Relevant authorities and stakeholders in the building sector should create awareness encouraging every prospective builder to incorporate all elements of sustainable building construction, through regulations and policies.

v. Novel solutions such as composites and use of flame retardant and preservative treatments should be employed at every stage of construction involving timber.

vi. Specialist in the construction field should encourage the use of composite and concrete enhanced timber wherever necessary.

The implementation of the above stated recommendations will go a long way in contributing to the knowledge of sustainable buildings through the use of timber and its benefits. However, there is no doubt that despite all the findings on the subject matter, further research can still be done

\section{REFERENCES}

[1] Akadiri, P.O. (2012). Development of sustainable assessment criteria for building materials selection, vol.19 pp. 666-687.

[2] Buchanan, A. and Honey, B. (1994).Energy and carbon Dioxide implications of Building construction energy and Building,20; 205-217.

[3] Bootle, K. (1983). Wood in Australia; Types, Properties and uses. McGraw-Hill Book Company

[4] Chris, A. (2007). Building configuration and seismic design Department of building development, United States of America

[5] Apu, S.S. (2003). Wood Structure and Construction Method for Low-cost Housing. International Seminar/ Workshop on Building Materials for Low-Cost Housing, September 7-28, Indonesia

[6] Ferguson, I, La Fontaire, B. ,Vinden, P., Bren,L., Hateley, R. and Hermesec, B. 1996, Environmental properties of timber, Research Paper commissioned by

[7] Forest Industries Association of Tasmania (FIAT) article "Embodied Energy" 2004.

[8] Nolan, G. (1994). The Culture of Using Timber as a Building Material in Australia. Proceedings of the pacific Timber Engineering Conference. Australia.

[9] Townsend, P. and Wagner, C. (2000).Timber as a Building Material: An Environmental Comparison against Synthetic Building Materials. National Association of Forest Industries.

[10] Adedeji, Y.M.D., and Ogunsote O.O (2004) .Modern techniques in building Structures and components in Nigeria. A paper delivered at the department of architecture, Federal University of Technology, Akure.

[11] Ogunsote, O.O. (1993). An Introduction to Building Climatology- $A$ Basic Course for F Architecture Students. Ahmadu Bello University, Zaria. the Forest \& Wood Products Research \& Development Corporation.

[12] Forest and Wood Products Research and Development Co-operation (FWPRDC), (2003) Environmental benefits of building with timber technical report issue 2, march 2003

[13] Lawson, W.R. (1996). Timber in building Construction; Ecological implications. Research paper commissioned by the (FWPRDC) and the Tasmanian Forest Research Council Inc. 


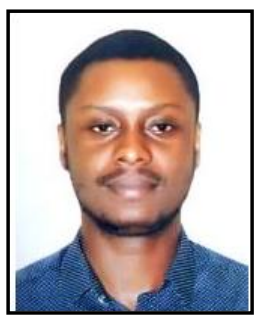

1. Author's Profile

Name: OSORE, Oludare Temitope.

Institution: The Federal Polytechnic, Ilaro

City Name: Ilaro

Country: Nigeria

Academic qualifications:

a) Master of Technology (M.Tech) in Architecture

b) Bachelor of Technology (B.Tech) in Architecture

Area of interests

a) Architectural Design

b) Architectural Sciences

c) Place making

d) Sustainable Architecture

e) The Built Environment

f) Computer Aided Design \& Drafting and Building Information Module 